\title{
Relationship between Secondary School Students'Level of Testwiseness and their Performance in Mathematics in Bauchi Metropolis of Bauchi State, Nigeria
}

\author{
A. Yusuf Mustapha (P.hD) \\ Department of Educational Foundations, Faculty of Education, University of Jos, Nigeria
}

\begin{abstract}
This research was conducted to find out whether or not there exist a relationship between the variables- levels of testwiseness and performance in mathematics among secondary school students in Bauchi metropolis. The study which used survey and correlational research designs was guided by two research questions and three hypotheses. The instruments for data collection were the results of the State-administered mock SSCE Mathematics examination and a Students' Testwiseness Questionnaire.Percentages, Pearson Product-Moment Correlation, Chi-square test and the t-test for independent samples were used for the data analysis. Findings revealed that more than half the numbers of students have low and moderate level of testwiseness; a positive relationship exists between level of testwiseness and students' performance while no relationship was found between gender and level of testwiseness. It was recommended that mathematics teachers in secondary schools in the metropolis need to consciously make instruction in test-taking skills part of their teaching sessions especially among femalestudents and students who are not resident in the schools, if they are to help them to maximize their performance in the subject.
\end{abstract}

\section{Background of the Study}

Mathematics as a subject is important in the technological development of every nation and its place in the advancement of knowledge especially Science-based courses cannot be overemphasized. However, over the years, performance of candidates in Mathematics in Nigeria has been on a downward trend especially at the secondary school level (Ozigbo, 1992).For example, Mustapha, 2012 posited that performancein WAEC/SSCE Mathematics for the period 2010 - 2012 shows that performance was poor with only $15.4 \%$ passes at credit level on the average while failure rate within the same period was as high as $72.8 \%$ (p.2). Also, Ayodele (2001, p.6) documented the trend of performance from 1996 to 1999 for English Language, Mathematics, Agricultural Science, Biology, Government and Economics using bar graphs and established that "the bar for F9 in English and Mathematics was much higher than those for other subjects combined".

Some factors that could be held responsible for the dismal state of performance of students in Mathematics include difficult nature of subject-matter, poor teaching methods, and attitude of both teachers and students to the subject (Attah, 2007). However, issues which bother around nature of the Mathematics tests and examinations and conditions of testees at the time of examinations are often neglected. Such issues include the level of skills possessed by the student taking the test and the presence or absence of anxiety among the students. These factors have been found to have significant effect on students' performance in Mathematics tests.Mathematics teachers at the secondary school level often neglect the issue of the extents to which students possess the requisite test taking skills to take tests and examinations in Mathematics.

Testwiseness (variously called test-taking skills, test expertise or test sophistication) emanates from testees regular taking of examinations and can confer a significant advantage to the experienced testees over those that are not experienced.It was Thorndike (1951) who first brought forth the concept of testwiseness as a variable in test performance. He sees it as a prominent source of score variance on cognitive tests second in influenced only to individual's cognitive ability. Millman, Bishop and Ebel (1965, p.707) see testwiseness as the "subjects' ability to utilize the characteristics and formats of the test and/or the test taking situation to receive high score". They are also of the view that testwiseness is logically independent of the examinee's knowledge of the subject-matter for which the items supposedly measures. Mustapha (2001) had found out in a study that the nature and level of possession of test-taking skills is an important factor in the performance of students especially in Mathematics tests.

Apart from the usual awareness that a test is approaching and a general idea of what to expect in such test, a student need to be able to give a good account of himself/ herself in the test otherwise they may not be able to maximize their performance in the test. Testwiseness is that quality possessed by a student at a particular period which enhances his/her performance in a test. The issue of possession of these skills has however, not been given considerable attention in Nigeria (Mustapha, 2009). Some students have good understanding of 
subject-matter, good reading ability but cannot manage their testing time wisely. Some other students are not able to interpret test instructions while some others generally cannot give a good account of themselves in a test. Also, while some are anxious in examination halls, some others do not know how to prepare for test. There are also technical skills which students need to possess in order to improve their performance. The needsfor testees to be conversant with those skills that will help them maximize their performance in tests/examinations have been emphasized by writers (Mueller \& Wasser, 1977; Oosterhof, 1990; Mustapha, 2006\& 2012).

Before now, early researchers (Leonard, 1968 \&Merlin, 1968) in their individual studies have found evidence to accept the hypothesis that testwiseness may be an important source of variance in test performance.More recently, Marshall (1997) found out that testwiseness scores were related to performance on both multiple-choice and non-multiple-choice portions of the examinations that was administered to one hundred and fifty business students.

Bauchi metropolis is located at the southern fringes of Bauchi State, Nigeria and is made up of a number of densely populated settlements with over sixty-eight secondary schools in the metropolis. While most of the schools are government owned, private individuals and organizations also own and run a few schools. The schools are either boarding or day with over eighty percent been single-sexed schools. Since the students take the Junior Secondary School Certificate Examinations (JSCE) and Senior School Certificate Examinations (SSCE) conducted by the West African Examinations Council (WAEC) and the National Examinations Council (NECO) respectively like their counterparts in other secondary schools in Nigeria, the students are expected to be testwise so that they canmaximize their performance school subjects especially in Mathematics examinations. The problem of this study therefore, is to find out the effects oftestwiseness on secondary school students' performance in Mathematics examination in Bauchi metropolis of Bauchi State, Nigeria.

\section{Research Questions}

1. To what extent are secondary school students in Bauchi metropolis testwise?

2. What is the level of performance of secondary schoolstudents in Mathematics in Bauchi metropolis? Hypotheses

1. Secondary school students' level of testwiseness is not significantly related to their performance in Mathematics in Bauchi metropolis.

2. Students' level of testwiseness is not significantly related to their gender in the metropolis.

3. There is no significant difference in the performance mean score of male and female students in Mathematics in the metropolis.

\section{Method and Procedure}

\section{Design of the Study}

The study used the survey research design which is reflected in the use of Students' Testwiseness Questionnaire (STW-Q) which was developed and validated by the researchers and the results of the Mock SSCE examinations to collect data from secondary school students in the metropolis.

\section{Population and Sample of the Study}

The population of the study was all the senior secondary school three (SSS 3) students in government owned senior secondary schools in Bauchi metropolis three students in the schools selected for the study. A sample of students from four schools in each of the category- day, boarding, boys only and girls only were used for the study. The day and boarding schools are however co-educational.In each school, $20 \%$ of the students were selected to constitute the sample of the study. Stratified sampling technique was used to select the samples from the day and boarding schools. This is because there are male and female students in the school. However, the simple random sampling technique was used to select the sample in the boys- and girls- only schools. In all, 330 male and 278 female students were involved in the study.

\section{Instruments for Data Collection}

Results of students' performance in the mock Mathematics examinations and STW-Q were used for collecting data for the study. The mock examination is typically taken by students in SSS3 i.e. the final year. The examination which is conducted by the State Ministry of Education is administered about two to three months before the main examinations and the result is used to determine the extents to which candidates have been prepared and are ready for the main examinations. The schools also use the result to identify students' areas of weaknesses and give them extra coaching in those areas. The examination is usually graded like the final WAEC and NECO SSCE examinations thus: 0-39 (F), 40-44 (E8), 45-49 (D7), 50-54 (C6), 55-59 (C5), 60-64 (C4), 65-69 (B3), 70-74 (B2), and 75-100 (A1).

The second instrument used for the research- STW-Q was made up of two parts. The first part required the students to supply only two background information:Name of School and gender while the second part has 
40 items that measure level of possession of testwiseness and rated using the Likert scale- Very Much Like Me (VM); Much Like Me (ML); Unlike Me (UL); Very Much Unlike Me (VMU); and Not Sure (NS) which were scored 4,3, 21 , and 0 respectively for positive items and the other way round for negative items. The instrument which was developed and validated and had been used for some other researches had a reliability coefficient of 0.81 when pretested in Jos Metropolis of Plateau State. This made the instrument reliable for the study.Permission was sought from the authorities of the sampled schools to give the students the questionnaire to respond to just before the commencement of the mock Mathematics examination. In order to control for extraneous variable such as response sets andexamination misconduct, the students were counseled beforehand and told that their responses to items of the questionnaire was for research purpose only. They were told not to write their names on the answer sheet.

\section{Method of Data Analysis}

Cut-off points were established for determining students' level of testwiseness using high, moderate and low. Since there are 33 items on the STW-Q and Likert scale was used, the minimum and maximum score on the questionnairewere 0 and 132 respectively. The cut-off intervals used were 0-65; 66-99 and 100-132 which represent Low, Moderate and High level of testwiseness respectively. The students were categorized based on these and thereafterfrequency counts and percentages were used to answer research question one. For research question two, mock examination results were collected from the schools, graded and thereafter, frequency counts and percentages were also used. Hypothesis one was tested using Pearson Product-Moment Correlation (PPMC)at 0.05 level of significance.For hypothesis two, the Chi-square test of independence based on a $3 \mathrm{X} 2$ contingency table (Low, Moderate and High vs. Male and Female) was used to test the hypothesis at 0.05 level of significance. Hypothesis three was tested using t-test for independent samples at 0.05 level of significance.

\section{Results and Discussions}

Students' response to the STW-Q shows that in all $51 \%, 23 \%$ and $26 \%$ of the students fall within the category Low, Moderate and High level of testwiseness respectively. Analysis of the response to STW-Q by gender revealed that male students generally have high level testwiseness when compared with their female counterparts. Table one below shows the trend of students' response.

Table 1: Level of Testwiseness by Gender

\begin{tabular}{|c|c|c|c|}
\hline \multicolumn{4}{|c|}{ Gender } \\
\hline Level of Testwiseness & Male & Female & Total \\
\hline Low & $125(40 \%)$ & $185(60 \%)$ & 310 \\
\hline Moderate & $86(61 \%)$ & $54(39 \%)$ & 140 \\
\hline High & $119(75 \%)$ & $39(25 \%)$ & 158 \\
\hline Total & 330 & 278 & 608 \\
\hline
\end{tabular}

When students' responses were analyzed based on school, the emerging trend was that students in the boarding school had a far higher level of testwiseness than all other categories of students. As a matter of fact, the eleven top most students in the STW-Q were all from the boarding schools and there were eight males and three females among these.

Table 2: Level of Testwiseness by School-type

\begin{tabular}{llllll}
\hline Level of Testwiseness & \multicolumn{2}{c}{$\begin{array}{l}\text { School type } \\
\text { Day }\end{array}$} & Boarding & Girls only & $\begin{array}{c}\text { Boys } \\
\text { only }\end{array}$ \\
\hline Low & 91 & 37 & 146 & 36 & 310 \\
Moderate & 83 & 18 & 20 & 19 & 140 \\
High & 21 & 109 & 16 & 12 & 158 \\
\hline Total & 195 & 164 & 182 & 67 & 608
\end{tabular}

Hypothesis one was rejected since there exists a significant relationship $(+0.79)$ between students' level of testwiseness and their performance in Mathematics. In the case of hypothesis two, significant relationship was not found between level of students' testwiseness and gender leading to retention of the hypothesis. Hypothesis three was retained since the t-test analysis that was done provide evidence that significant difference was found between the mean score of male and female students. The difference was however, in favor of male students. 
Table 3: Summary Table for t-test Analysis

\begin{tabular}{|c|c|c|c|c|c|c|c|}
\hline Variable & $\mathbf{N}$ & $\mathbf{x}$ & $\mathbf{S}$ & df & t-calc & t-crit & Decision \\
\hline Male & 330 & 42.11 & 36.54 & & & & \\
\hline Female & 278 & 53.4 & 33.2 & 606 & -23.54 & 1.64 & Accept $_{\mathrm{O}}$ \\
\hline
\end{tabular}

The findings of this study is in tandem with the view of researchers ((Mueller and Wasser, 1977; Oosterhof, 1990; Mustapha, $2001 \&$ 2006) on the importance and need to deliberately make attempt to improve students' level of testwiseness in schools. This is because if there is a positive relationship between the two variables, then deliberate efforts must be made and geared towards raising students' level of testwiseness so that their performances can also be improved.

Conscious efforts need to be put in place to beef up the students' awareness of- and possession of the skills that can give them advantage as far as performance in mathematics examination is concerned. The difference that was found between performances in the examination with the male students been better is a pointer to the fact that the deliberate attempt that isrecommended is an important factor that can create a level playing ground among the students. This is coming from the background that Thorndike (1951) had already posited that testwiseness is a prominent source of score variance on cognitive tests second in influence only to individual's cognitive ability. Employing the use of knowledge and understanding of skills of how to respond to- and handle items in mathematics examinations in secondary schools should assume a popular place in the classroom interactions of mathematics teachers with their students.

\section{Recommendations and Conclusion}

Students need to be able to do well in mathematics tests and examinations s in secondary schools in Nigeria.The way and manner students in secondary schools are trained in acquiring the necessary test-taking skills will go a long way in improving their performance in mathematics at the secondary schools level. Schools and teachers need to be conversant with gains that can be made when the students are highly skilled in taking mathematics tests and examinations while thestudents need to know and appreciate the need for possessing of these skills. What needs to be done is to create awareness for teachers to see the importance and the benefit of having students improve on the level of their test-taking skills. Once teachers know the importance of this factor, they will go a long way in making sure their students are exposed to these skills. The teachers on their own can be helped to understand what is involved in this through seminars, workshop and school enlightenment campaigns.

\section{References}

[1] Attah, B.G. (2007). An evaluation study of the impact of remedial programme on performance of mathematics students at the undergraduate level in the University System. An Mphil/Ph..D presentation, University of Jos, Jos.

[2] Ayodele, S.O. (2001). The challenges of secondary education in the twenty first century. Keynote address at the Curriculum Organization of Nigeria (CON) conferment of fellowship ceremony held at the multi-purpose auditorium of the University of Jos, March, 14th.

[3] Ebel, R.L. \&Frisbie, D.A. (1991).Essentials of educational measurement ( $6^{\text {th }}$ edition). New Jersey: Prentice Hall.

[4] Leonard, H.K. (1968). The effects of test-taking practice on pupil test performance. American Educational Research Journal, 5(4), p. 616.

[5] Marshal, A.G. (1997). An examination of the relationship between answer changing, testwiseness, and examination performance. The Journal of Experimental Education, 66(1), 49-60.

[6] Merlin, W. (1968).The influence of test-wiseness upon achievement.Educational and Psychological Measurement, 28, 413-420.

[7] Millman, J., Bishop, H.I., \& Ebel, R. (1965).An analysis of test wiseness.Educational and Psychological Measurement, 25(1), 707726.

[8] Mueller, D.L. \& Wasser, V. (1971). Implication of changing answers on objective test items. Journal of Educational Measurement, $14,9-14$

[9] Mustapha, A.Y. (2001). Teaching testwiseness as an integral part of classroom instruction in

[10] Nigerian schools: The teacher's role. In P.N. Lassa \& J.A. Aghenta (Eds.), Proceedings of the $16^{\text {th }}$ Annual Congress of the Nigerian Academy of Education. Jos: Nigerian Academy of Education.

[11] Mustapha, A.Y. (2006).Strategies for a more potent cure for examination malpractice.Journal of the Nigerian Society for Educational Psychologists (NISEP), 4(1), 79-86.

[12] Mustapha, A.Y. (2009). A survey of secondary school teachers' level of possession of test-taking skills in Jos Metropolis of Plateau State. Journal of Educational Technology and Instruction (JETI), 67-70.

[13] Mustapha, A.Y. (2012). Analysis of psychometric properties of Junior Secondary School Certificate Mathematics Examinations in Plateau State. Unpublished P.hD. Thesis, University of Jos, Nigeria

[14] Oosterhof, A.C. (1990). Classroom application of educational measurement. Ohio: Merrill Publishing Company.

[15] Ozigbo, I.G. (1992). Teachers' remedial mathematics to technical education students.Paper presented at the $33^{\text {rd }}$ Annual Conference of STAN, University of Nigeria, Enugu Campus. 